\title{
TITLE:
}

\section{Piping Failure of a Metro Tunnel Construction}

$\operatorname{AUTHOR}(\mathrm{S}):$

Lee, Wei Feng; Ishihara, Kenji

\section{CITATION:}

Lee, Wei Feng ...[et al]. Piping Failure of a Metro Tunnel Construction. Proceeding of TC302 Symposium Osaka 2011 International Symposium on Backwards Problem in Geotechnical Engineering and Monitoring of Geo-Construction 2011: 73-82: 共同研究（一般共

ISSUE DATE:

2011

URL:

http://hdl.handle.net/2433/173843

RIGHT: 


\title{
Piping Failure of a Metro Tunnel Construction
}
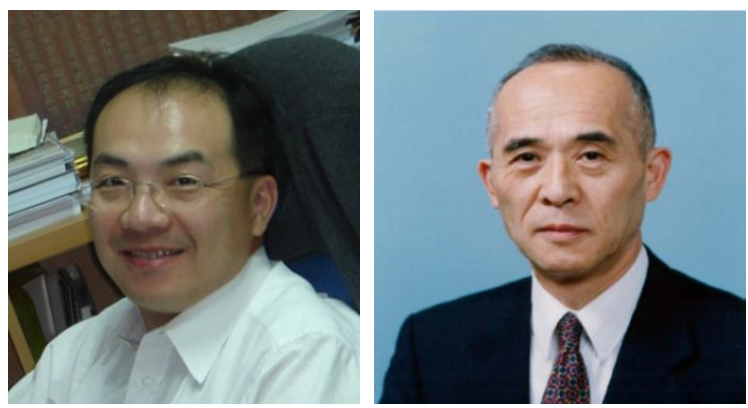

Wei F. Lee

Associate Research Professor, National Taiwan University of Science and Technology, Taiwan

Kenji Ishihara

Professor, Chuo University, Japan

\begin{abstract}
In this paper, the forensic investigation of a subway tunnel construction failure occurred in Kaohsiung, Taiwan is presented. The studied construction failure occurred during a cross-pass tunnel excavation of a shield tunnel construction work of the Kaohsiung Mass Rapid Transit system, and had resulted in severed tunnel collapse and extensive ground failure that even reached to ground surface $30 \mathrm{~m}$ above the tunnel depth. In order to investigate such a serious construction failure, particular soil testing programs and geophysical testing methods were carried out to access the possible failure scenario of the investigated case. Information presented in this paper is hoped to be helpful to improve engineers' knowledge for preventing similar construction risks.
\end{abstract}

\section{OUTLINE OF THE INCIDENCE}

Subway construction had been underway in eastwest direction in the central part of Kaohsiung. Upon finishing the tunnel construction by the method of earth-balanced shield, the corridor connecting the two tunnels (up-line and down-line) was constructed by means of what is called the NATM method involving open excavation with the help of steel -framed support and injection. Then, a vertical shaft $3.3 \mathrm{~m}$ in diameter was excavated to provide a sump for water collection in the middle of the corridor in open dry conditions with the support of the H-shaped circular beams. When the shaft excavation reached a level $4.95 \mathrm{~m}$ from the floor of the corridor, a chunk of wet soil tumbled out from the southern wall of the shaft at the bottom.

The small collapse was followed by steadily increased outflow of mud water. The amount of water increased minute after minute. This breakage led to undermining the already built-up tunnels, accompanied by an inflow of soil and water from the rips opened at the junction on the ceiling between the corridor and tunnel. This breakage cul- minated eventually in a large scale collapse of the tunnel structure involving formation of two caveins on the ground surface.

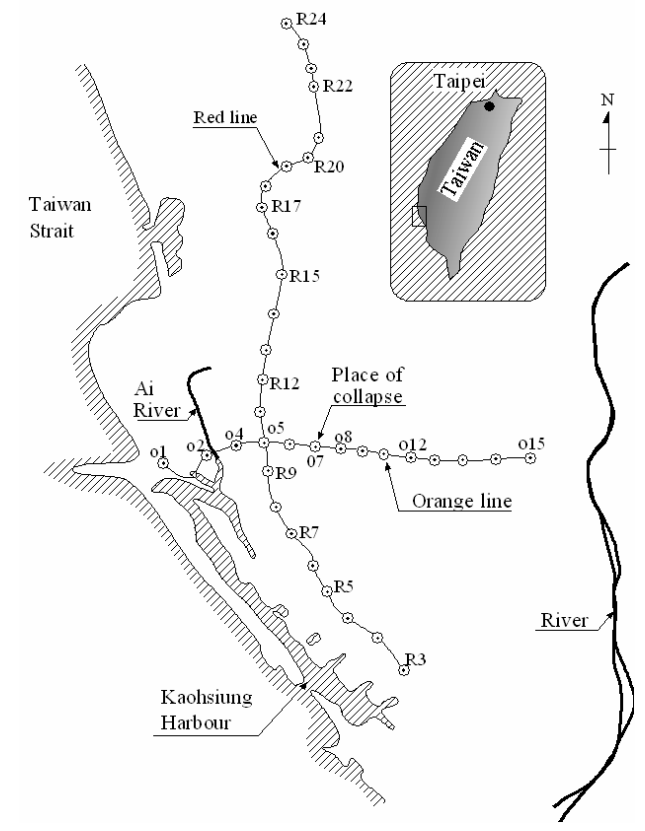

Figure 1. The location of the collapse 


\section{DESCRIPTION OF THE SITE CONDITIONS}

The location of the collapse is shown in Figure 1 and the feature of the cave-in on the ground surface is displayed in Figure 2. A bird-eye view over the cave-in is displayed in Figure 3. The plan and side view of the tunnel are shown in Figure 4. It is to be noted that there was an underground roadway called Chung Cheng underpath just above the subway tunnel. The dual tunnels were constructed by the tunnel boring machine (TBM) which can advance by rotating a large steel disk equipped with cutting blade, while the cutting face is balanced by the mud pressure.

The soil profiles at the locations $\mathrm{BO} 29$ and $\mathrm{BO} 30$ shown in Figure 2 are indicated in Figure 5, where it can be seen that the deposits are comprised predominantly of silty sand with occasional layers of low-plasticity clay (CL) to a depth of $40 \mathrm{~m}$. The blow count, $\mathrm{N}$-value, in the standard penetration test is shown to increase with depth and to have a value of 20 to 30 at the depth where the sump for water collection was excavated.

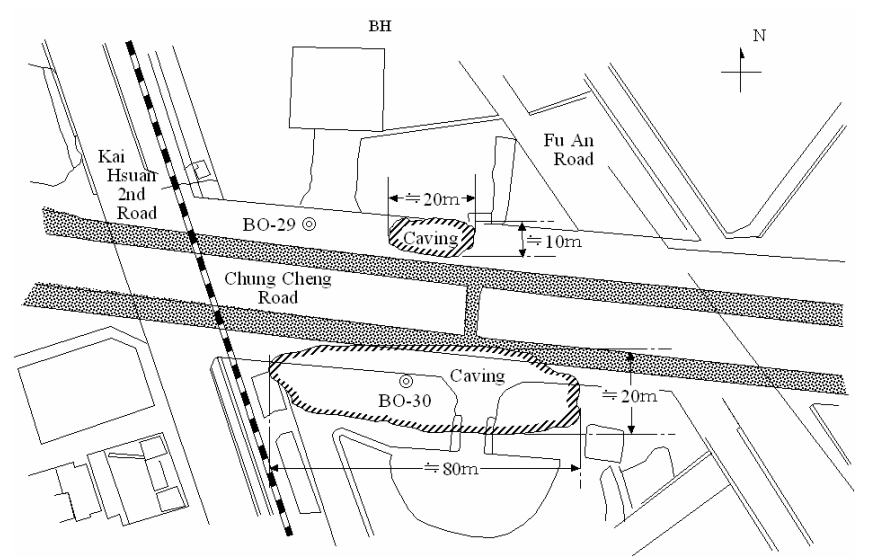

Figure 2. Features of the cave-in in plan view

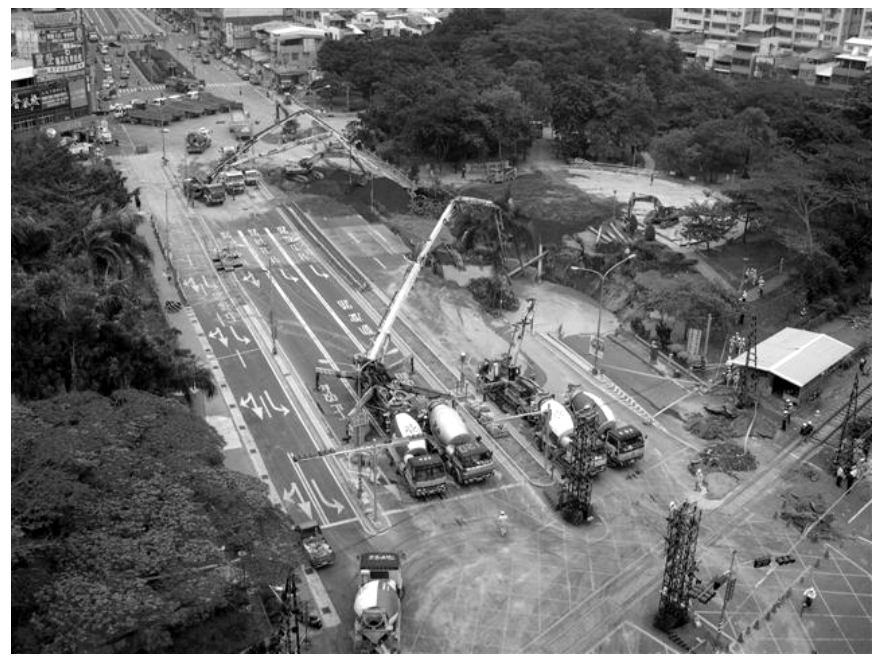

Figure 3. A bird-eye views over the cave-in in Kaohsiung

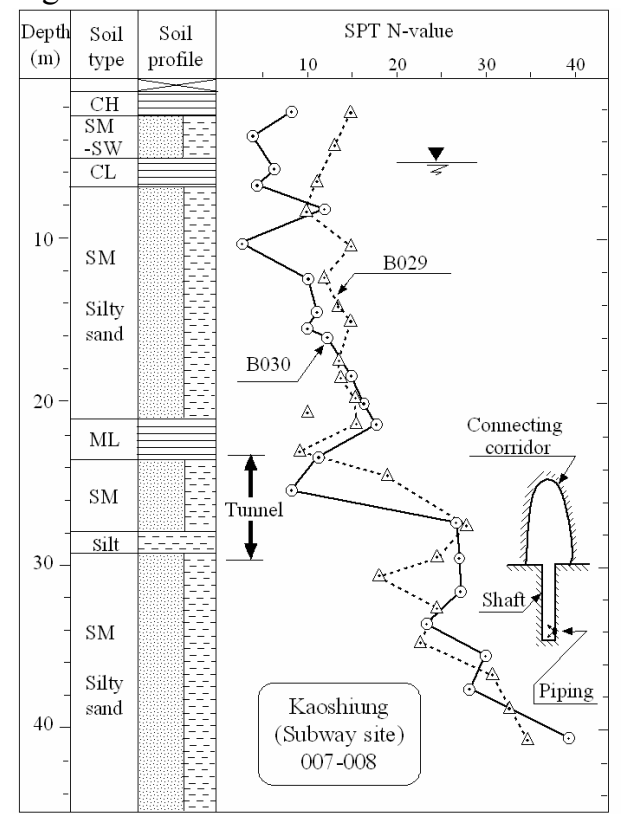

Figure 5. Soil profile at the site of collapse

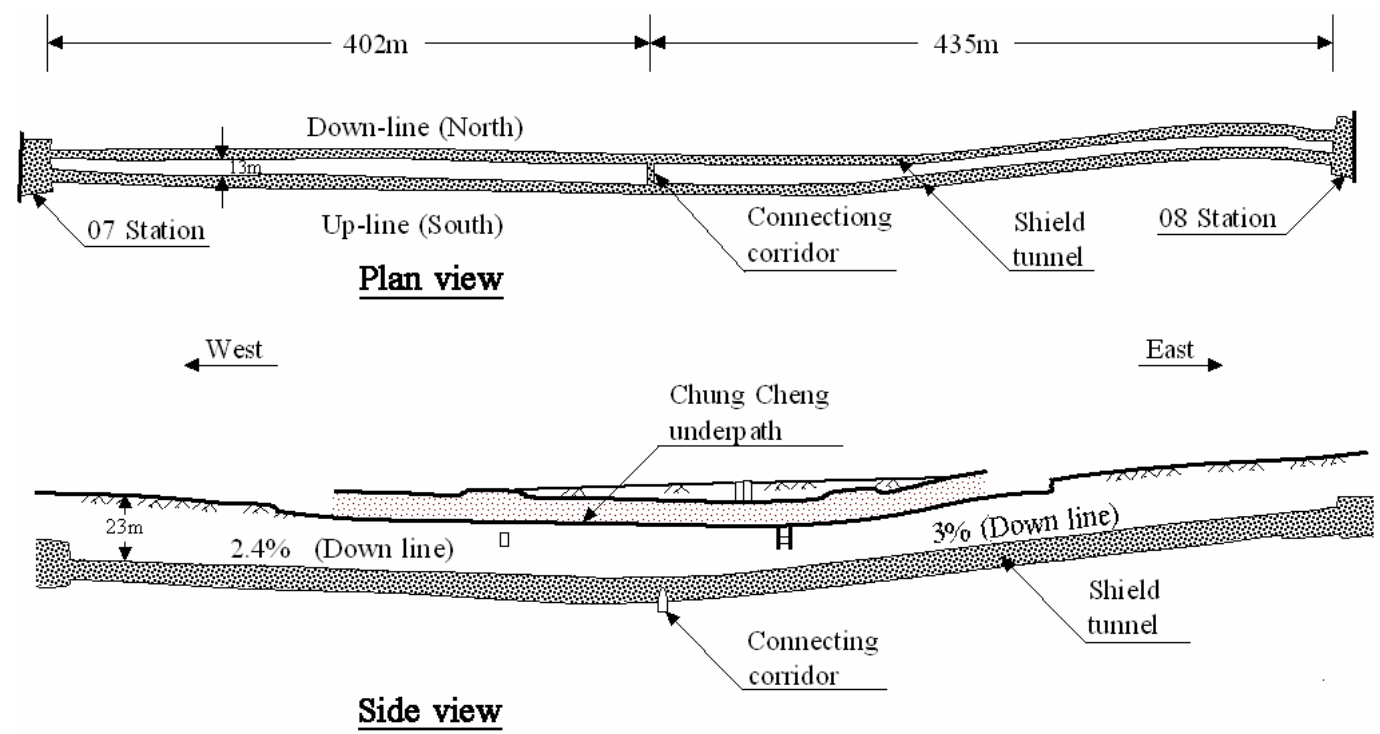

Figure 4. Plan and side view of the tunnel 


\section{IMMEDIATE RETROFIT WORK}

\subsection{Ground stabilization}

The first stage of immediate retrofit work is mainly focused on backfilling the sinkholes. Total volume of $9000 \mathrm{~m}^{3}$ sand, concrete, and aggregates was dumped from ground surface to fill the caves developed from the deep seated corridor. In addition to backfill, remediation grouting and curtain grouting were also applied from both north and south sides of the car pass to try to stabilize the underground structures and further confine the damaged ground. Figure 6 shows the layout and the total injection volume of grout for the immediate work. In the mean time, double layered concrete walls were also constructed inside the damaged tunnels to retain debris. Ground stabilizing measures were found to be able to effectively slow down the progressive settlement of the ground.

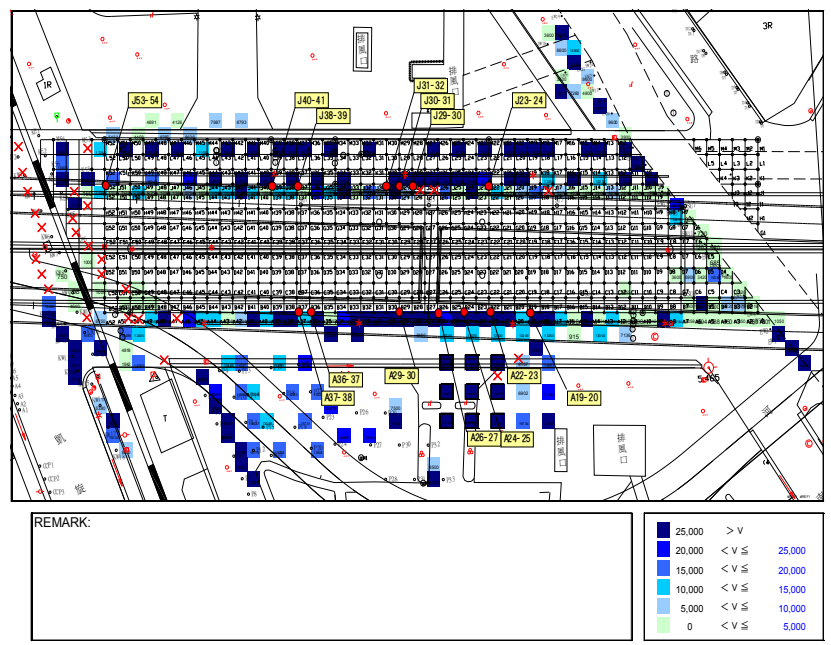

Figure 6 Layout and total volume of grout applied (TCRI, 2006)

\subsection{Maintaining hydrostatic condition}

As described in previous paragraphs, two tap water supply pipes were broken and leaking large amount of water into the damaged ground. In order to stabilize the liquefied soil, water were reinjected into the tunnels after completion of the retaining walls (Figure 7). The injected water was in an effort to maintain stable ground water table at the depth of damaged tunnels. The injecting process was in operation for about seven days before the target ground water table was reached. This hydrostatic maintaining measure was found to be able to effectively control the ground subsidence and provide stable access for further retrofit work.
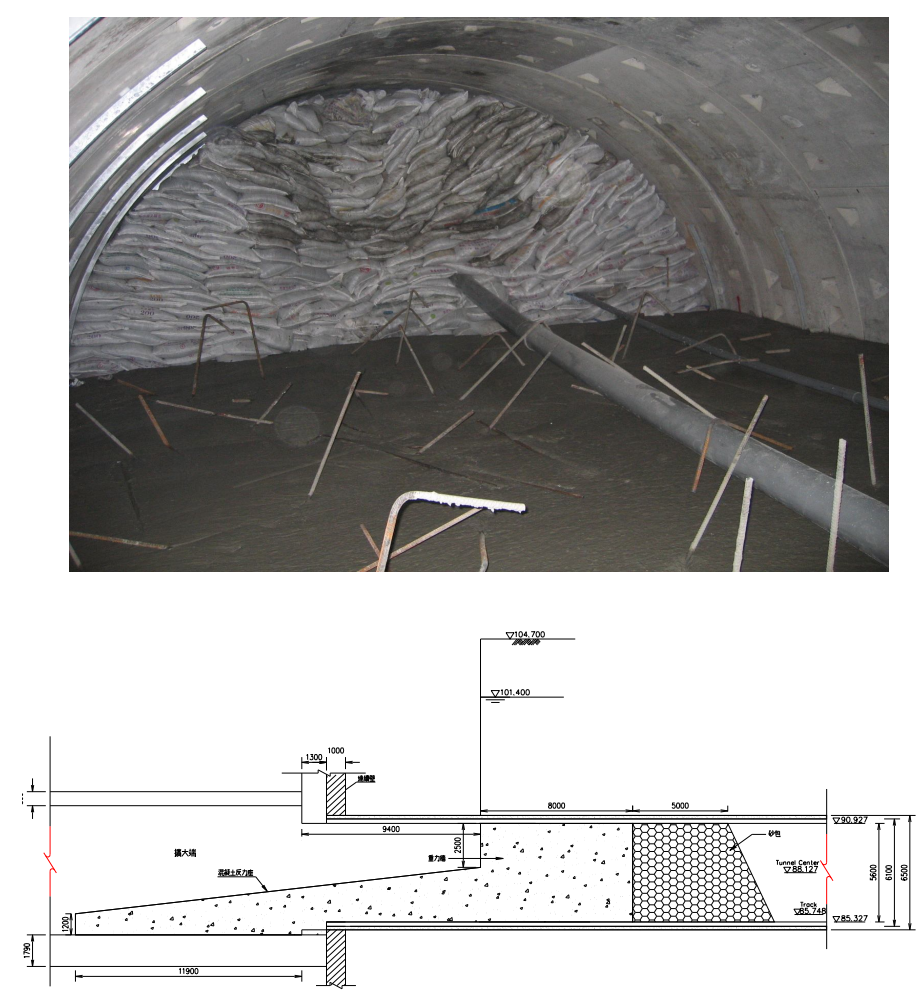

Figure 7 Schematic drawing and photo of the retaining wall.

\section{PIPING FAILURE OF THE TUNNEL}

On December 4, 2005, the piping occurred at $3: 30 \mathrm{p} . \mathrm{m}$. at the very last stage of excavation of the sump. A block of silty sand was detached from the south wall at the bottom of the excavation which is located at a depth of $35 \mathrm{~m}$ from the ground surface. The circumstance at this time at the bottom of the sump excavation is illustrated in details in Figure 8.

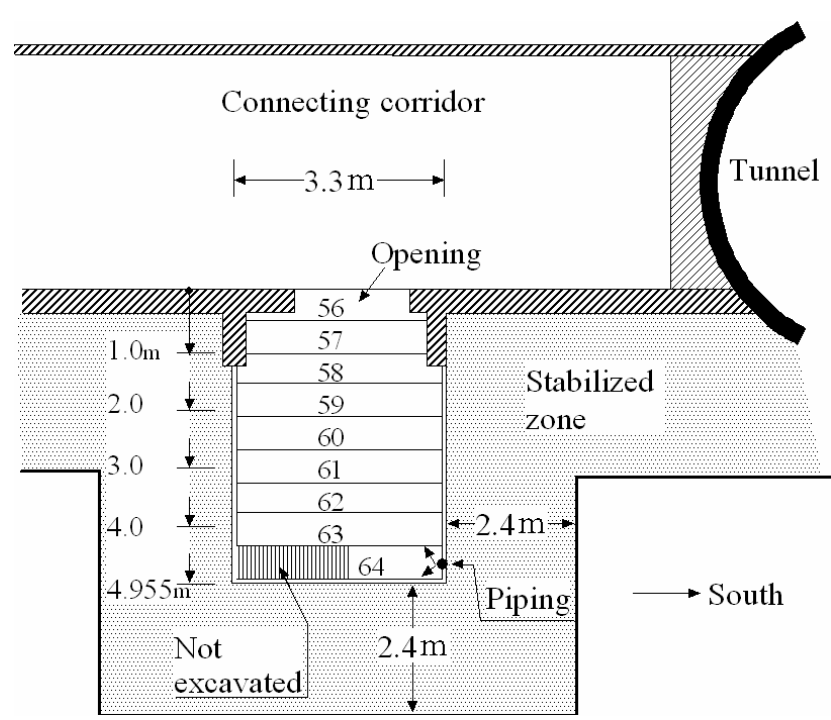

Figure 8. Details of the excavation for the sump and initiation of piping 
A sequence of the events after triggering the piping which are likely to have occurred is illustrated in the cross sections in Figure 9. The blackish mud water continued to come out in the sump with increasing volume. Two men at work at the bottom strove in vein to clog the hole by dumping sand bags from the corridor. About one hour later, the sand bags were seen moving around in the sump as illustrated in Figure 9(b). At this stage, the workmen closed the entrance to the sump by placing a steel lid and several bars for its support as illustrated in Figure 9(c).

It is believed that the mud water flowed into the sump from the bottom through a single hole probably with a diameter of about $30 \mathrm{~cm}$. This assumption would hold true in the light of the fact that the zone stabilized by the jet grouting could not so easily broken down in the horizontal direction, and a weak zone might have existed in the form of vertical pipe.

About two hours later, engineers at spot heard squeaking sounds of breaks at segment joints of the tunnel on the south, accompanied by mud water cascading from the ripped joints of segments at the ceiling. It appears likely that because of the underscoring of the bottom portion, the stabilized zone subsided together with the tunnel body, resulting in the stepwise settlement in the longitudinal direction. The probable feature of the breakage at this stage is illustrated in Figure 9(c).

Around 10:20p.m., the fall-off of the soil above the ceiling had spread upwards and, assisted by the slipping along the vertical wall of the motorway structure, soil mass fell down into the tunnel. This resulted in creation of a large cave-in on the ground surface on the south side. At this time, two mains $60 \mathrm{~m}$ and $30 \mathrm{~m}$ in diameter for water supply were broken releasing a large amount of water for a prolonged time. This breakage of buried pipes appears to have transferred the collapsed soil deposits into more flowable debris.

The feature of the collapse propagation as above would be understood more vividly by visualizing the sequence of events that might have occurred in the longitudinal direction. These features are described in Figure 13(a) through 10(d). Figure 13(c) and (b) shows the progress of the collapse from 3:30p.m. to 5:30p.m. on December 4, 2005. Figure 13(c) indicates the breakage of the tunnel, segment by segment, resulting in the fall-off the debris from the offsets of the segments in the ceiling on the east side. On the north side undermining of the tunnel body did occur as well as shown in Figure 9(d), resulting in the sinking of the tunnel together with the large block of the stabilized zone. This led to the breakage of the segment joints on the north side and allows the mud water cascading mainly through the opening at the junction between the portal and the adjacent segment. The length of the tunnel in which the debris packed in the entire cross section was as long as $130 \mathrm{~m}$ on the west side and $80 \mathrm{~m}$ on the east side in the up-line on the south, as shown in Figure 13(d). Thus, another cave-in occurred on the north side, as seen in Figure 2. The amount of soils and concrete dumped to fill the caves was $12,000 \mathrm{~m}^{3}$ and the volume of water inflow from the $60 \mathrm{~cm}$ diameter water main lasting about 18 hours until 11:50 p.m. next day was approximately $2,000 \mathrm{~m}^{3}$. Thus the total amount of debris was as much as $14,000 \mathrm{~m}^{3}$.
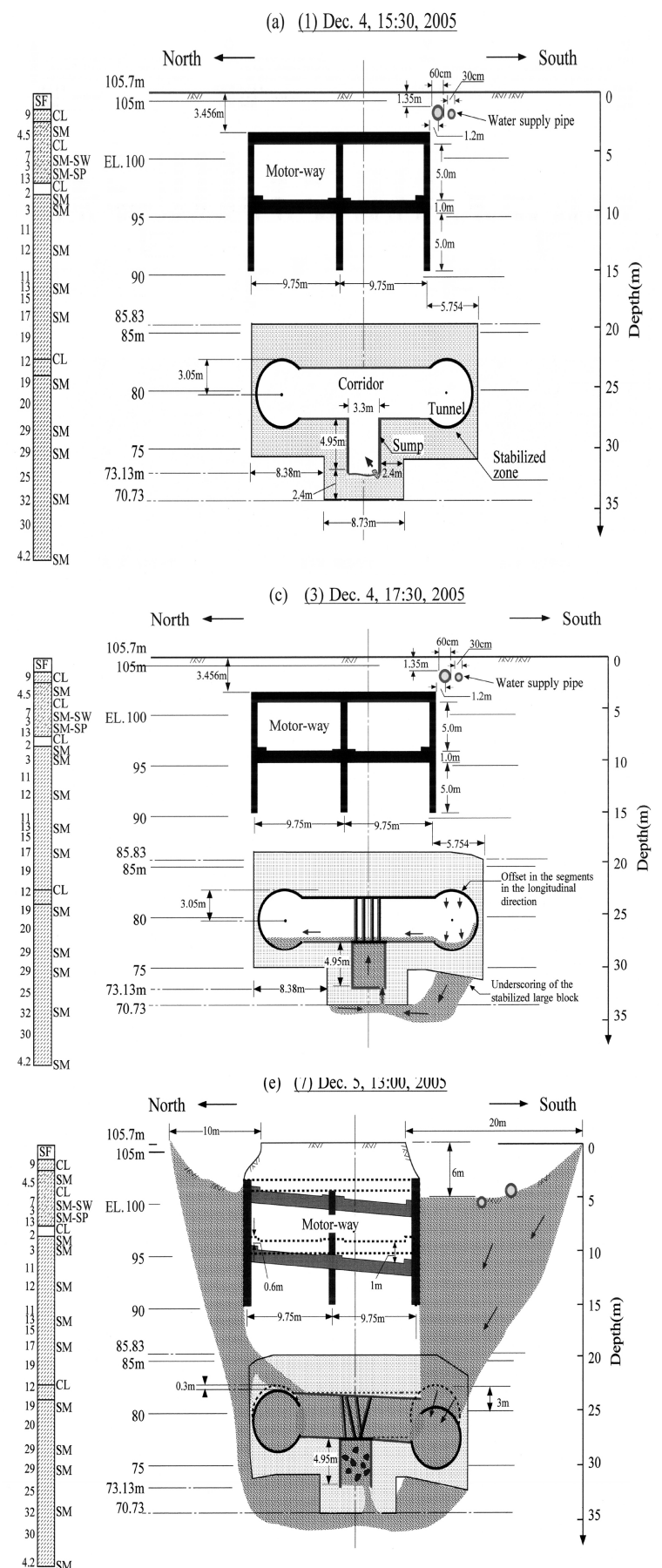

Figure 9. A sequence of likely scenario for progressing the piping failure. 
International Symposium on Backward Problems in Geotechnical Engineering TC302-Osaka 2011

West

(b)

(2) Dec. $4,17: 30,2005$

East

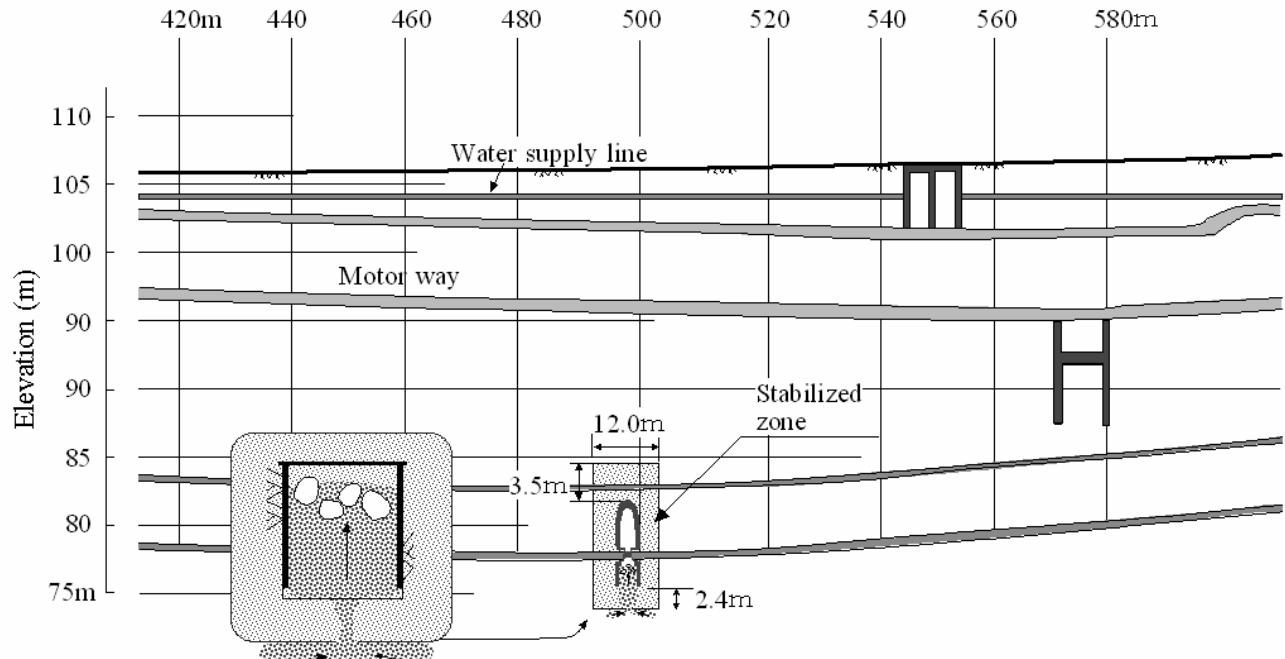

West

(c)

(3) Dec. 4, 22:20, 2005

East

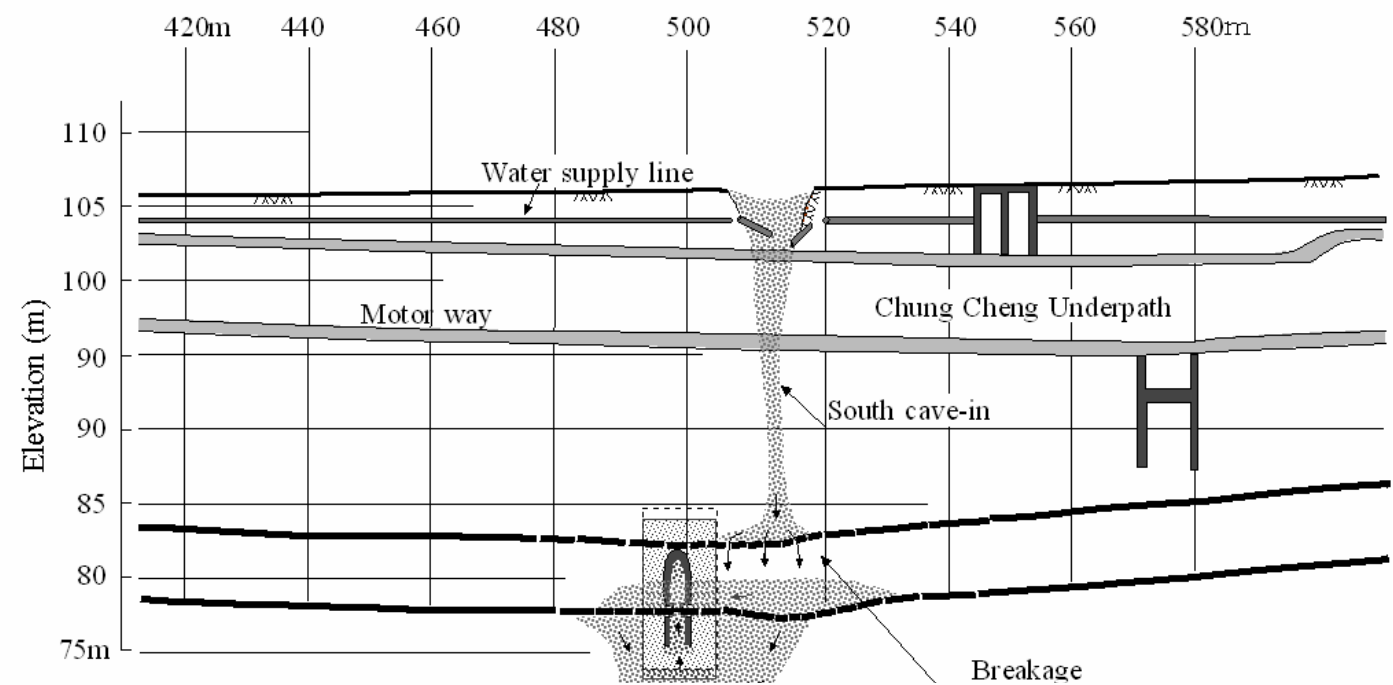

(4) Dec. 5, 13:00, 2005

West

(d)

Breakage

$\stackrel{\text { West }}{\longleftarrow}$

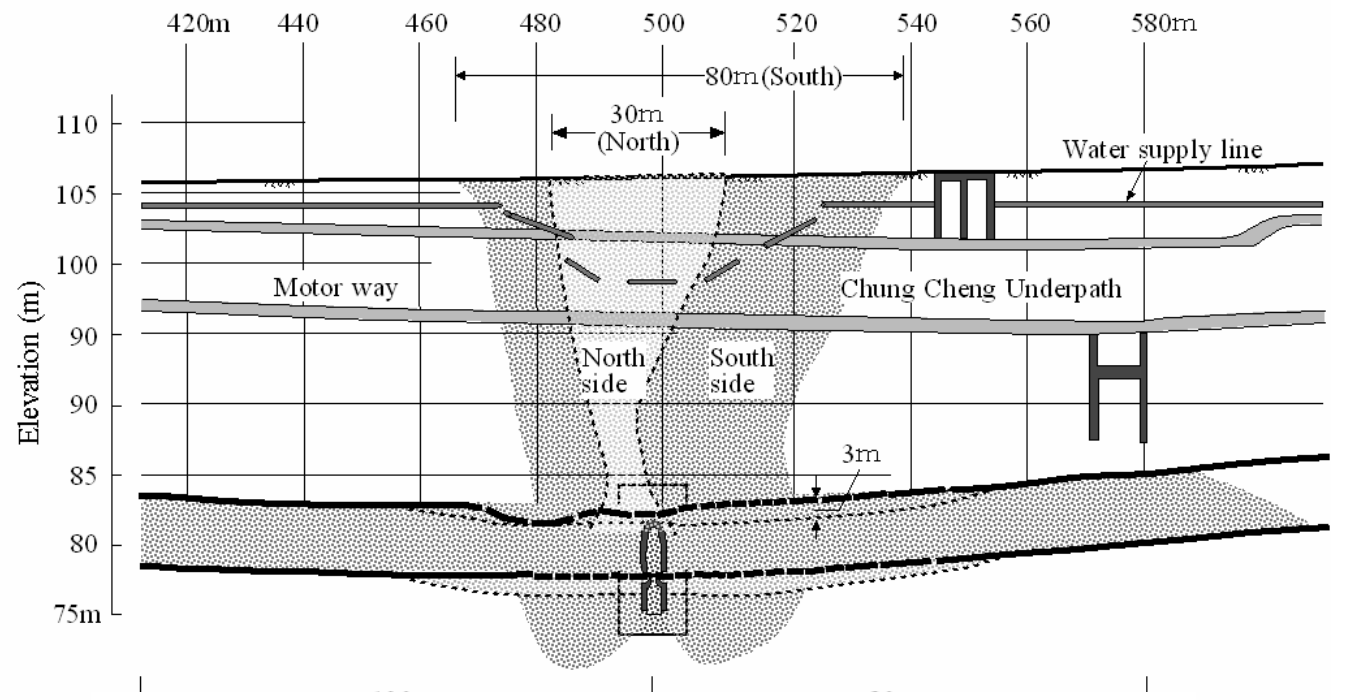

Figure 13. A sequence of likely scenario in the longitudinal direction 


\section{RESISTIVITY PROFILE IMAGINE (RIP) TESTING}

\subsection{RIP method}

In this study, surface 2D RIP testing was conducted to probe ground condition, and to check the effectiveness of remediation grouting right after the accident. Figure 11 shows the layout of the 2D RIP testing. As depicted in the figure, six survey lines in north-south direction and one in east-west direction were installed in an attempt to cover the damaged area; and hopefully to identify different soil conditions and underground structures. As described in previous paragraphs, the corridor was surrounded by grout material which was installed to stabilize the ground prior to excavation. Large numbers of sand bags and backfill material were dumped into the surface sinkholes to stabilize the disturbed ground after the event. Ground conditions were fairly complicated when the 2D RIP survey was conducted..

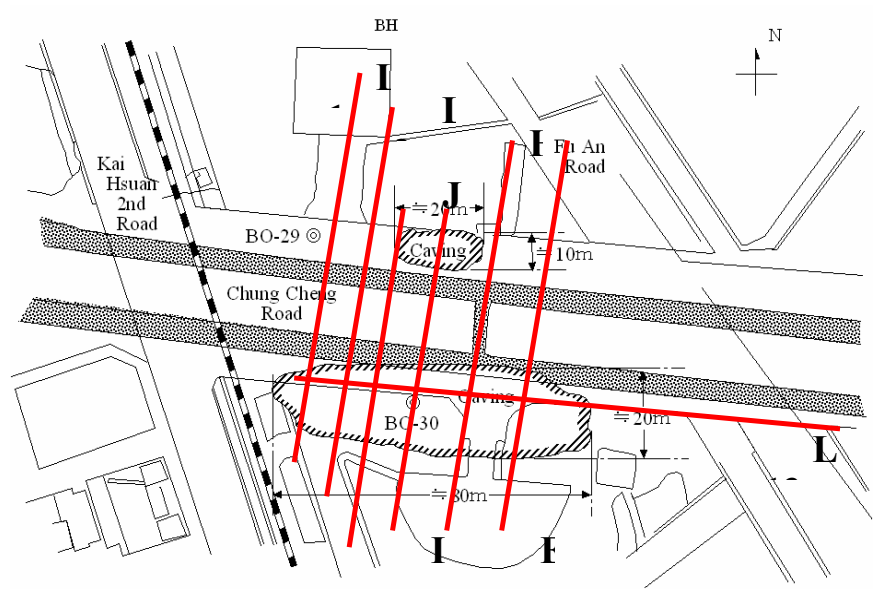

Figure11. Layout of the RIP test.

\subsection{Test results}

Figure 12 shows the results of 2D RIP in cross sectional profiles. In the figures, cold colors, from green to deep blue, represent low resistivity materials as the disturbed ground with larger volume of ground water content. On the contrary, warm colors, from yellow to red and brown, represent high resistivity material such as grout materials or cemented backfill. Underground structures shown in imagines of 2D RIP tend to be distorted from rectangular shapes into upward shell shapes. As depicted in Figure 12, despite the imagine distortion, area in between the underground carpass and the subway corridor were identified as in seriously disturbed condition. At locations of Line L2 and Line $E$, which are the east and west boundaries of the soil improvement block of the damaged corridor, soil beneath the subway tunnels was also found to be severely agitated by the piping failures. This observation implied that the subway tunnels outside the grouted area might subside and resulted in dislocations of tunnel ring segments. Imagines shown in Figure 12 also indicate that immediate remediation grout treatments have effectively reached both sides of the corridor as displayed in warm color. By interpreting the 2D RIP results, failure schemes shown in Figure 9 were possibly pictured to pursuit causes of the failure. Borehole probing was also conducted at the same time when 2D RIP survey was performed in an effort to validate the scale of the damaged tunnel portion.
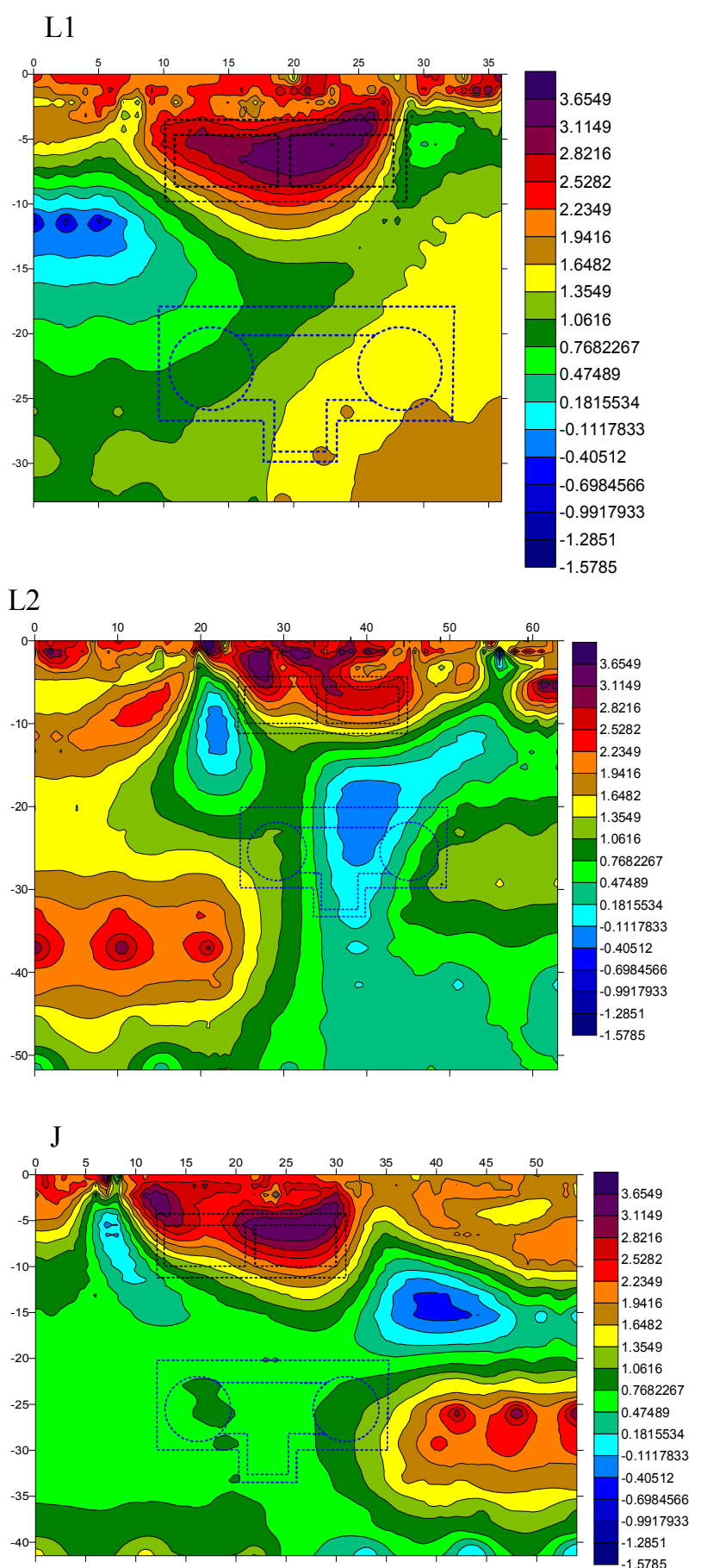

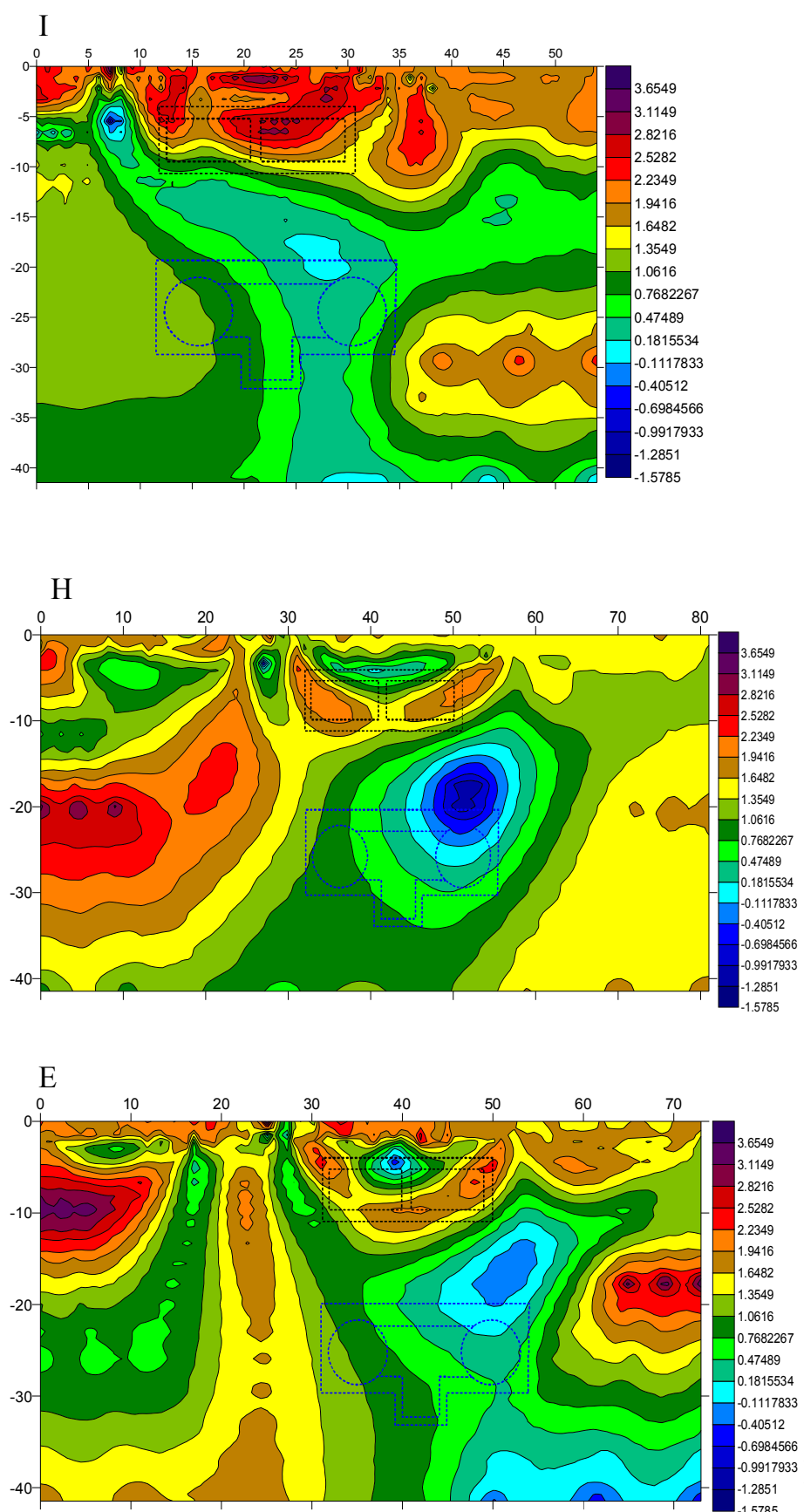

Figure 12. Results of RIP tests

\section{INVETIGATION INTO CAUSES OF FAILURE}

After the collapse, the Committee of Investigation was organized by the Kaohsiung Mass Transit Authority and its work commissioned to National Taiwan Construction Institute in Taipei. Even after comprehensive studies and discussions, it appeared difficult to single out definitive causes with proven evidences. However there were several points agreed upon by the Committee which could be summed up as follows.
(1) It was obvious from the testimony of the two men at work that the phenomenon of piping was responsible for triggering the collapse.

(2) The reasons why the piping was initiated were conceived variously. One of them was existence of seepage-prone weak zones resulting from imperfect overlapping in the arrangement of the soil-cement columns created by the jetgrouting method. In fact, because of the obstructions in the ground, it was difficult to install some of the jet-grouted columns exactly in plumb and the overlapping of adjacent columns at the elevation of the piping is estimated less than $60 \mathrm{~cm}$.

(3) The hydraulic pressure at the depth of $34 \mathrm{~m}$ where the piping was initiated was estimated as being about $300 \mathrm{kPa}$ and the length of conceivable shortest path for seepage was $2.4 \mathrm{~m}$ as counted from the bottom level of the stabilized zone. Thus, the hydraulic gradient at the time of the piping is estimated as having been of the order of $i=30 \mathrm{~m} / 2.4 \mathrm{~m}=12.5$ which was fairly high.

(4) Thus, it is expected that the critical hydraulic gradient for unstable seepage was about 12.5 , although the reason for this to occur remained unidentified. It was also suspected rather strongly that the silty sand in the area of Kaohsiung might be possessed of a characteristic which is vastly prone to internal erosion as compared to soil deposits existing in other parts of the world. Thus, once the piping develops, the deposit is least self-healing and tends to become easily unstable.

\section{PRONENESS OF LOCAL SOILS TO .09917933 INTERNAL EROSION}

There have been several small collapses reported in other sections of subway construction in Kaohsiung. In fact, it was a concern among geotechnical engineers working there that the fines in sand deposits in Kaohsiung is highly non-plastic and easy to flow. Thus, one of the key issues for forensic diagnosis for piping of the local soil was considered to focus on the investigation into the extremely flowable nature of silts in Kaohsiung area which has not ever been addressed elsewhere.

As is well-known, the susceptibility of a given silty sand to internal erosion can be understood from two points of views, that is, generic reason and durability or resistively. 
(1) If an aggregate of a soil is comprised of two major groups each having significantly different particle sizes, the grains with smaller size can move easily through pores of the matrix formed by larger particles. Thus, if such a soil with a gap grading is subjected to seepage flow, the smaller particles can be easily detached and washed away. This is the generic concept underlying the criterion for the design of filters in rockfill dams. However, it is normally applied to the type of soils in a range of particle sizes which are larger than those of silt sands encountered in Kaohsiung area.

(2) The condition as to whether or not a given soil actually suffers the piping collapse is expressed in terms of the critical hydraulic gradient. In fact, the experiments by Skempton and Brogan (1994) showed that the critical hydraulic gradient, ic, for the occurrence of piping in gap-graded sand-gravel mixture could be as low as $0.2-0.3$ as against $\mathrm{i}=0.9-1.0$ for clean sands. This would hold true for soils with the range of particle size coarser than the silty sand in Kaohsiung. To the author's knowledge, there appears to be no study ever performed to clarify the vulnerability to piping or internal erosion for silty sands or sandy silts subjected to the seepage flow. Thus, this issue was taken up as a new problem area deserving further scrutiny to identify causes of the collapse in deep-seated excavation.

\section{LABORATORY TESTS ON INTERNAL EROSION}

With respect to the piping or erosion, there would be three types of problems to be distinguished depending upon the range of grain size of soil materials in question. These are shown in a graphical form in Figure 13. The segregation piping has been the target of extensive studies in the past in association with the filter criteria for the design of rock fill dams. There are many studies reported in this context such as those by Terzaghi (1939), KennyLau (1985, 1980), Skempton-Brogan (1994) and Sherad (1979).

Erosion in clay-silt materials has been investigated by Sherad (1979) in response to the problem emerging from occasional failure of low-height earth dams which occurred upon water filling in Australia and U.S. The grain sizes associated with erosion or gully formation has been known to lie in the range indicated in Figure 13. It is known that dispersive nature of clayey soils is a dominant factor for inducing gulley or erosion tunnels in the clay fills. Tests for chemical analysis and pinhole tests were suggested as means to identify the dispersive nature of the fine-grained soils.

The outcome of the grain-size analyses for the silty sand at Kaohsiung has shown that the soil there belongs neither to the broadly graded gravelly sands for the segregation piping nor to the dispersive clay related to the erosion or gulley formation. In fact, the grain size in Kaohsiung soil lies midway in the range of silt and sand, as shown in Figure 13, which is coarser than the dispersive clay and finer than the soils related with segregation piping.

Thus, the collapse of the silty sand in the subway construction in Kaohsiung was considered to have posed a new challenge and addressed a novel problem area. The solution for this is not yet settled, but performing some tests was regarded as a useful attempt to shed some light on this problem. In this context, a set of pinhole tests and measurements of specific surface test were performed as described below.

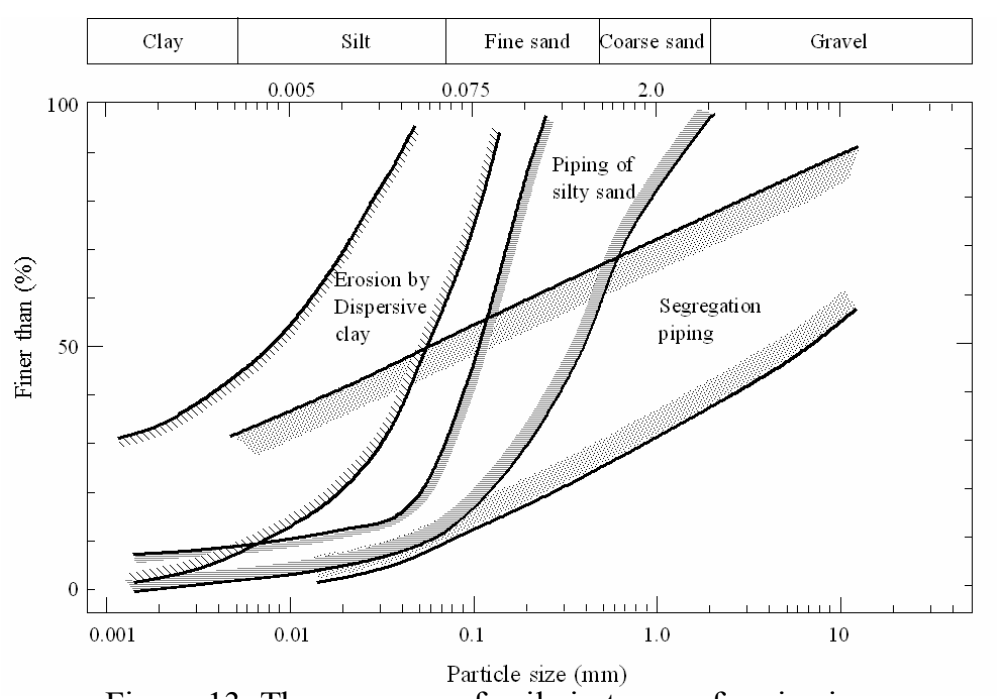

Figure 13. Three groups of soils in terms of grain size range associated with erosion and seepage instability

(a) Pinhole Tests

In order to examine the vulnerability of the silty sands at Kaohsiung to the internal erosion or piping, what might be called "Pinhole test" was carried out. The layout of the test system is displayed in Figure 14. The sample $4 \mathrm{~cm}$ thick and $5.17 \mathrm{~cm}$ in diameter was sandwiched by highly pervious gravel layers at the top and bottom with filter meshes placed between the sample and gravel. A vertical hole $3 \mathrm{~mm}$ in diameter was drilled as shown in Figure 14. Water was then circulated through the sample. In this type of test, water is supposed to flow mainly through the pinhole. If the silty portion is erodible, the water coming out is expected to be muddy, but otherwise the water transparent. 


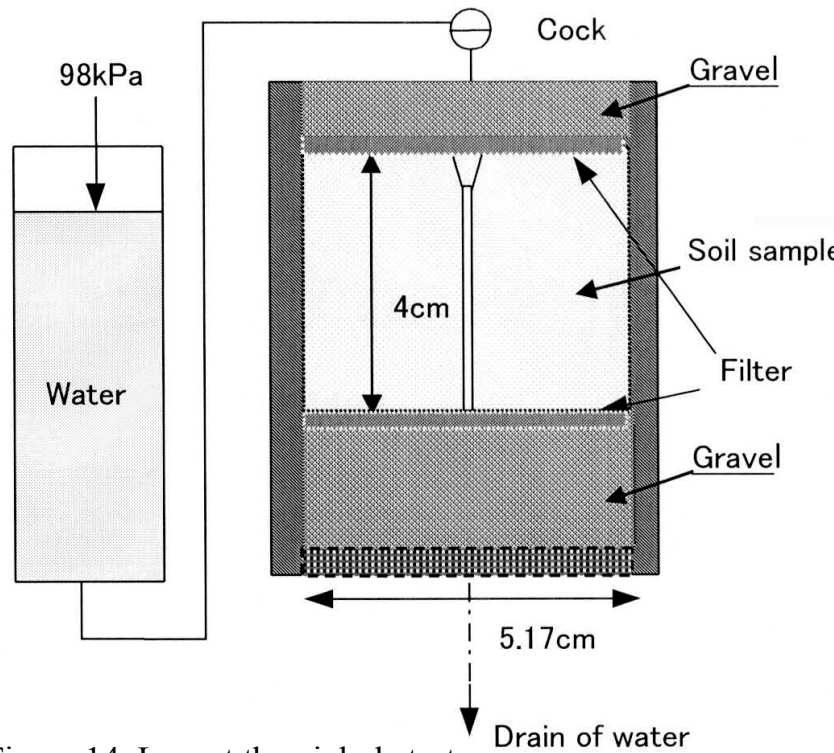

Figure 14. Layout the pinhole test

The silty sand from Kaohsiung tested had a grain size distribution as shown in Figure 15. For comparison sake, another material from a site in Chiba, Japan was secured and used for the same testing. The grading of this Japanese soil was almost the same as indicated in Figure 15. It is to be noticed that both silty sands had an average grain size of about $\mathrm{D}_{50}=0.075 \mathrm{~mm}$ and fines content was about $50 \%$. The physical characteristics of these two materials are shown in Table 1. The two samples were compacted so as to have the same wet density of $1.902 \mathrm{~g} / \mathrm{cm}^{3}$. A sample from Kaohsiung as prepared for the pinhole test is displayed in the middle of Figure 16 and gravel layers to be placed on top and at the bottom are shown on both sides of Figure 16. The procedures for testing were as follows.

(1) Water was circulated first slowly with a low pressure through the sample to ensure saturation.

(2) Water was then circulated under a pressure of $98 \mathrm{kPa}$ and colour of water coming out of the sample was observed. Pictures were taken every one-minute. Water percolation was continued for 5 minutes

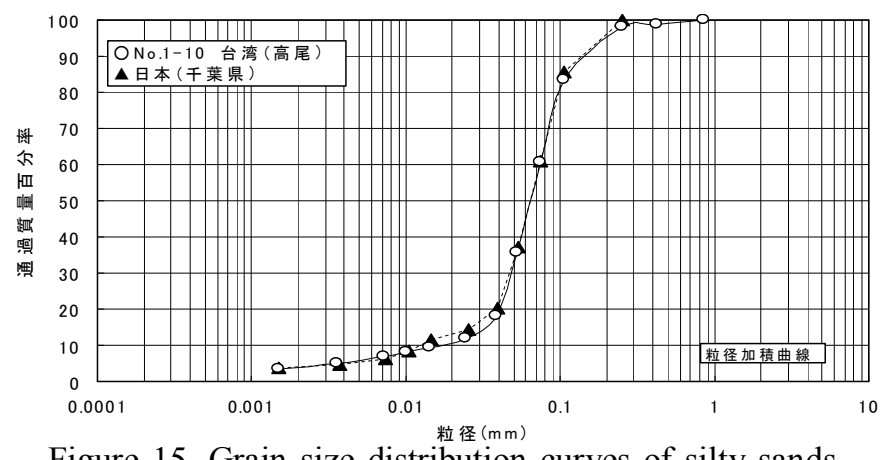

Figure 15. Grain size distribution curves of silty sands used for the pinhole tests
Table 1 Grading of two materials used for the pinhole tests

\begin{tabular}{|l|c|c|}
\hline \multicolumn{1}{|c|}{ Material } & Kaohsiung sand & Japanese sand from Chiba \\
\hline Dry density $\rho_{d}\left(\mathrm{~g} / \mathrm{cm}^{3}\right)$ & 1.902 & 1.902 \\
\hline$D_{60}(\mathrm{~mm})$ & 0.0651 & 0.0654 \\
\hline$D_{50}(\mathrm{~mm})$ & 0.0746 & 0.0743 \\
\hline$D_{10}(\mathrm{~mm})$ & 0.0168 & 0.0124 \\
\hline$U_{c}$ & 4.443 & 2.51 \\
\hline Specfic gravity Gs & 2.733 & 2.708 \\
\hline
\end{tabular}

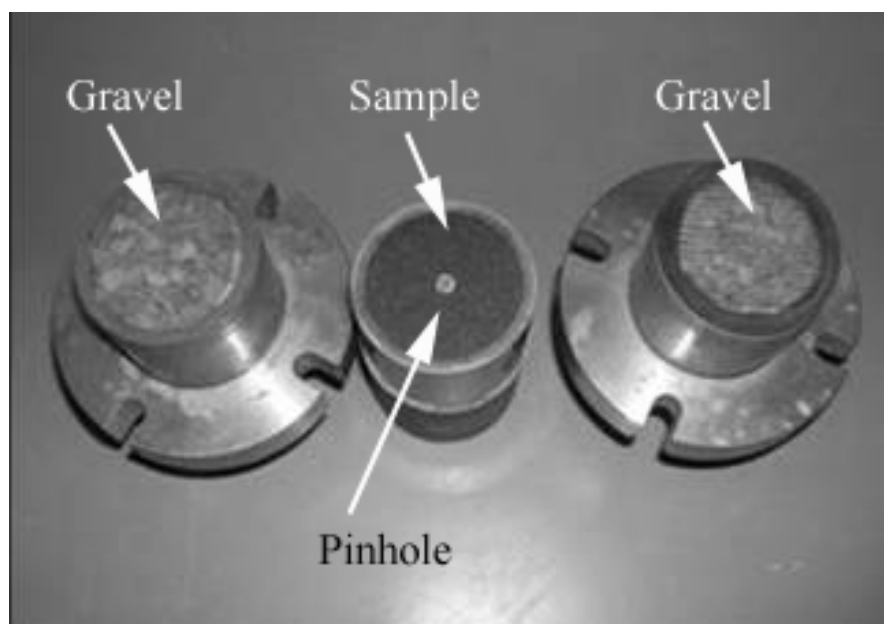

Figure 16. A samples from Kaohsiung for the pinhole test (the middle)

In the first series, the tests were conducted on disturbed samples, one from Kaohsiung and another from Japan. The result of the pinhole tests on a disturbed sample is presented in Figure 17. For the disturbed silt-containing sand sample from Kaohsiung, the pinhole is seen enlarging to a diameter of $5 \mathrm{~mm}$ from $3 \mathrm{~mm}$ as displayed in Figure 17(a). Correspondingly, the drained water from the bottom was muddy for the first one-minute period of water percolation as seen in the water colour in the left-side cup of Figure 17(b). The result of the pinhole test on the Japanese silty sand is shown in Figure 18. In contrast to the Kaohsiung soil, the circulation of water through the Japanese soil did not exhibit any appreciable change in colour in the first one minute of percolation as seen in Figure 18(b). There was no change in the pinhole diameter for the Japanese soil before and after water permeation except for a local collapse at the top. Thus, it may be conclusively mentioned that the silty sand from Kaohsiung is potentially susceptible to internal erosion as compared to the soil from Chiba, Japan, although they had almost the same grading. This is believed to stem from the highly non-plastic nature of the Kaohsiung silt contained in the sand. 


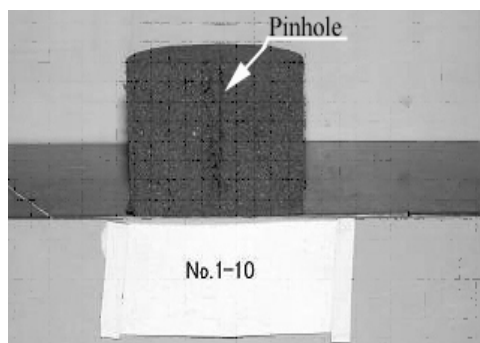

(a) Pinhole enlarged from $3 \mathrm{~mm}$ to $5 \mathrm{~mm}$, visible erosion

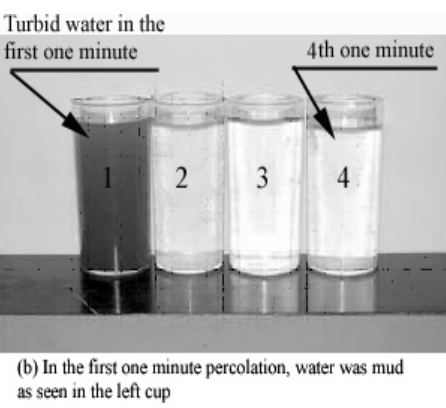

as seen in the left cup
Figure 17. Silt-contained sample from Kaohsiung

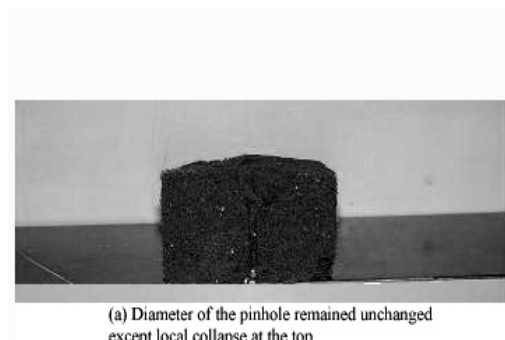

(a) Diameter of the pinhole ren
except local collapse at the top

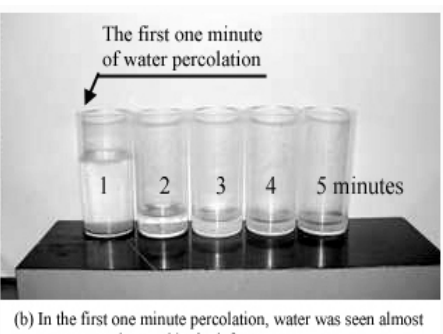

(b) In the first one minute percolation,
transparent as observed in the left cup
Figure 18. The results of the pinhole test on the Japanese silty sand

In the subsequent series, similar pinhole tests were conducted on undisturbed samples. The undisturbed sample from the depth of $14 \mathrm{~m}$ in Kaohsiung also demonstrated dirty blown colour in the first one-minute of percolation accompanied by the enlargement of the pinhole from 3 to $4 \mathrm{~mm}$, as displayed in Figure 19.

Two fine sand samples from a deposit at depth $22 \mathrm{~m}$ in Kaohsiung were tested likewise with the result that it is also vulnerable to internal erosion.

From the series of the pinhole tests as described above, it may be concluded that, no matter whether the soil is disturbed or undisturbed, the silt ingredient contained in the Kaohsiung sand is not only non-plastic but also highly erodible being susceptible to piping as compared to other silts with the same gradation such as those in Japan.
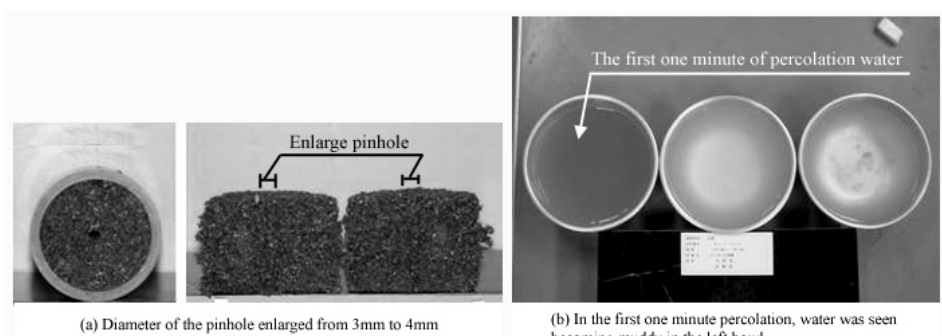

Figure 19. Pinhole tests on undisturbed samples from Kaohsiung

\section{LESSONS LEARNED FROM THE INCIDENT IN KAOHSIUNG}

In the practice of subway construction in Kaohsiung, it has been known that the silty sand in that area is of peculiar nature being highly susceptible to erosion due to seepage. Although the silt portion is known to be non-plastic, there has been no way further on to scrutinize the nature of the silt. In an effort to grope for some gauge, what is called pinhole test and specific surface test were conducted for the Kaohsiung silt and also for silt from Japan. The results of these tests have shown that the silt from Kaohsiung is more erodible and has a smaller value of specific surface area than the silt in Japan. This fact is indicative of the tendency of the Kaohsiung silt to be more liable to erosion as compared to other silts. The piping failure in the subway construction in Kaohsiung as described above is considered as a consequence of such a peculiar nature of the local soil which had not explored well. This incident is to be regarded as a typical example addressing an issue of new challenge in the area of geotechnical engineering. 